\title{
PEDAGOGIAS CULTURAIS NO SERIADO MODERN FAMILY
}

\author{
Luciana Kornatzki ${ }^{1}$ \\ Paula Regina Costa Ribeiro ${ }^{2}$
}

\begin{abstract}
Resumo: Este artigo tem por objetivo analisar algumas pedagogias culturais produzidas pelo seriado norte-americano Modern Family, a partir das suas diferentes configurações familiares, das relações de parentesco que se estabelecem e das personagens que o compõem. Entende-se que as mídias possuem pedagogias culturais que contribuem para a produção de percepções e entendimentos sobre o significado de família, assim como educam os sujeitos, pois são capazes de produzir subjetividades e interferir no modo como as pessoas percebem a si e ao mundo. As pedagogias culturais de família presentes em Modern Family são produtoras de novas identidades de ser pai, mãe, filho ou filha, bem como de todo um conjunto de relações de parentesco que mobilizam os sujeitos na constituição de suas subjetividades.
\end{abstract}

Palavras-chave: Pedagogias culturais. Seriado Modern Family. Família.

\section{CULTURAL PEDAGOGIES ON THE MODERN FAMILY SERIES}

\begin{abstract}
This article aims to analyze some of the cultural pedagogies produced by the North American series, "Modern Family", based on their different family configurations, the kinship relations that are established and the characters that compose it. It is understood that media have cultural pedagogies that contribute to the production of perceptions and understandings about the meaning of family, as well as educate the subjects, since they are capable of producing subjectivities and interfere in the way people perceive themselves and the world. The family cultural pedagogies present in Modern Family are producers of new identities of being father, mother, son or daughter, as well as of a whole set of kinship relations that mobilize the subjects in the constitution of their subjectivities.
\end{abstract}

Key-words: Cultural Pedagogies. Modern Family Series. Family.

1 Doutoranda no Programa de Pós-Graduação em Educação em Ciências (associação ampla FURG/UFRGS/UFSM) da Universidade Federal do Rio Grande - FURG. Membro do Grupo de Pesquisa Sexualidade e Escola - GESE. E-mail: lukornatzki@gmail.com

${ }^{2}$ Professora Titular do Instituto de Educação da Universidade Federal do Rio Grande - FURG; professora no Programa de Pós-graduação em Educação em Ciências (associação ampla FURG/UFRGS/UFSM) e no Programa de Pós-graduação em Educação Ambiental; líder do Grupo de Pesquisa Sexualidade e Escola GESE e bolsista de produtividade CNPq, nível 1C. E-mail: pribeiro.furg@gmail.com 


\section{INTRODUÇÃO}

O conceito de família tem sido constantemente debatido na contemporaneidade, evidenciando grupos que defendem o modelo tradicional nuclear, constituído por pai, mãe e filhos/as, assim como outros grupos que negam ser este o único modelo aceitável, lutando pelo reconhecimento das diferentes configurações familiares. A defesa de um único modelo acaba por produzir exclusões, preconceitos e discriminações contra os sujeitos que não se enquadram no padrão estabelecido. (GATO, 2015, MELLO, 2005, DIAS, 2015, FARIAS \& MAIA, 2009).

Família é entendida aqui como uma construção cultural (DIAS, 2015) que vem passando por modificações ao longo dos processos de transformações históricos e sociais, mas que hoje não depende exclusivamente de ligações biológicas. O que tem caracterizado uma família na contemporaneidade são as relações afetivas e/ou laços consanguíneos, envolvendo lutas e disposições jurídicas e políticas na sua constituição. Para Dias (2015, p. 131)

[...] nos dias de hoje, o elemento distintivo de família, que a coloca sob o manto da juridicidade, é a presença de um vínculo afetivo a unir as pessoas com identidade de projetos de vida e propósitos comuns, gerando comprometimento mútuo (grifos da autora).

Segundo a autora, o crescente pluralismo das relações familiares provocou um abalo na forma como se estrutura a sociedade. A família hoje não é mais dependente do vínculo promovido pela união civil. Esse reconhecimento resultou de conquistas por direitos civis de igualdade e liberdade que promoveram novas formas de se conceber essa instituição social (DIAS, 2015).

É possível perceber a contribuição que algumas mídias têm oferecido para a visibilização desses outros arranjos familiares, como o caso do seriado norte-americano Modern Family, que tem sido produzido e transmitido desde 2009. No Brasil este seriado está disponível em canais da Internet. As mídias podem, assim, produzir outras percepções e entendimentos sobre o significado de família, contribuindo para evidenciar suas diversas possibilidades.

Entende-se que as mais diferentes mídias, assim como este seriado, possuem pedagogias culturais que educam os sujeitos, pois são capazes de produzir subjetividades e interferir no modo como as pessoas percebem a si e ao mundo. 
Nesse sentido, este artigo tem por objetivo analisar algumas pedagogias culturais produzidas pelo seriado Modern Family, a partir das suas diferentes configurações familiares, das relações de parentesco que se estabelecem e das personagens que o compõem.

A mídia, entendida como um dispositivo pedagógico conforme Fischer (2002), atua na constituição dos sujeitos, de suas identidades e subjetividades, formando-os como sujeitos de determinados tipos de sociedades, atuando em seus modos de ser, de pensar e conhecer o mundo (FISCHER, 2002). O dispositivo pedagógico da mídia educa os sujeitos, visando o seu governamento, normalização e disciplinamento, ensinando-lhes modos de ser e estar na cultura e adequando-os à sociedade contemporânea. A mídia é, desse modo, instrumento de relações de poder que produz subjetividades dentro de uma determinada cultura.

Essa percepção possibilita um outro olhar para esse artefato na construção da ciência que a utiliza como objeto de estudo. Diante disso, Camozzato (2015, p. 517) aponta que a mídia "[...] tem sido fecunda para estudos que esmiúçam a sua gramática e as estratégias de atuação e direcionamento de condutas".

Para Giroux (2005) é importante pensar sobre o papel que a mídia exerce através de textos e imagens, os quais interferem na vida cotidiana dos sujeitos. Para ele,

[...] sob a rubrica da diversão, do entretenimento e da fuga, estão sendo produzidas esferas públicas massivas, que são consideradas como demasiadamente 'inocentes' para merecer uma análise política" (GIROUX, 2005, p. 136).

Com a face da diversão e do entretenimento, elas nos mobilizam, nos seduzem e nos tocam, fazendo com que não se perceba a educação que contribuem para produzir em cada sujeito. Em relação às imagens e textos presentes nas mídias, por exemplo em noticiários ou propagandas televisivas, Silva (2009, p. 140) afirma que

[...] do ponto de vista pedagógico e cultural, não se trata simplesmente de informação e entretenimento: trata-se, em ambos os casos, de formas de conhecimento que influenciarão o comportamento das pessoas de maneiras cruciais e até vitais.

Podemos incluir aí também as telenovelas, filmes, revistas e os seriados, que são em grande parte norte-americanos, disponíveis na Internet e em canais de TV aberta e por assinatura. A respeito do crescente consumo de seriados norte-americanos Lima (2013) cita os autores Elali e Silva (2012), indicando que 
[...] entre os produtos televisivos mais veiculados no mundo estão os seriados norte-americanos, que atualmente são vendidos para mais de 125 países, incluindo o Brasil. Além disso, outros indicativos da popularidade dos seriados é que este tipo de produto está entre os itens mais procurados para download na internet. Alguns se tornaram boxes de DVD mais vendidos (LIMA, 2013, p. 26).

Percebe-se assim a importância de pensar sobre esses artefatos, sobre os discursos que expressam, sobre as normas, regras e relações de poder que produzem. Costa, Silveira e Sommer (2003) alertam para que se perceba que as crianças e adolescentes permanecem por muito mais tempo diante da TV, e pode-se arriscar afirmar muito mais com seus computadores, celulares e tablets conectados à Internet, do que na escola. Esse fato tem possibilitado a expansão dos seus sentidos de realidade. É inegável que o consumo de informações obtido através desses artefatos contribui na construção de sentidos de si e do mundo. As autoras e o autor contribuem para pensar também que

[...] um noticiário de televisão, as imagens, gráficos etc. de um livro didático ou as músicas de um grupo de rock, [acrescenta-se os filmes e seriados] por exemplo, não são apenas manifestações culturais. Eles são artefatos produtivos, são práticas de representação, inventam sentidos que circulam e operam nas arenas culturais onde o significado é negociado e as hierarquias são estabelecidas (COSTA, SILVEIRA, SOMMER, 2003, p. 23).

Andrade e Costa (2015) postulam que as discussões relacionadas ao papel que o universo midiático tem exercido sobre a formação das pessoas tem confluído para a concepção do termo cultura da mídia, ou seja, a construção de um olhar sobre a implicação de artefatos como filmes, programas de rádio, TV, bem como os textos, vídeos e imagens disponíveis na World Wide Web (WWW) na educação das pessoas.

É preciso ressaltar aqui o rompimento de fronteiras possibilitado pela rede mundial de computadores que fazem chegar todo tipo de informação aos mais diferentes cantos do mundo. Isso ocorre com os seriados de televisão, hoje disponíveis em diversos sites, seja de forma gratuita ou por assinatura. Não é mais a TV, portanto, o reduto de filmes e séries, pois a Internet encontrou aí um campo fértil de comércio e em crescente expansão. Contudo, juntas, possibilitam chegar os mais diversos programas a um enorme contingente de consumidores/as, interferindo em seus processos de construção cultural e de luta por identidades. 


\section{ESTUdOS CULTURAIS, CULTURAS, PEDAGOGIAS: CONCEITUANDO AS PEDAGOGIAS CULTURAIS}

Este texto tem como fundamento epistemológico autores/as pertencentes aos Estudos Culturais, campo este que busca romper com a hierarquia das culturas, desconstruindo a ideia de alta e baixa cultura. Para Costa, Silveira e Sommer (2003) a transformação do significado de cultura rompeu com a segregação elitista que concebia a existência de apenas uma cultura válida, pensamento característico da modernidade, abrindo espaço para a pluralização de sentidos, para o reconhecimento das diferentes formas de expressão.

Nesse campo teórico, entende-se que toda produção humana, todo conhecimento, é cultural e que as relações sociais produzem cultura. Conforme indica Silva (2009, p. 139) "[...] todo conhecimento na medida em que se constitui num sistema de significação, é cultural”.

Os seriados televisivos, ao reverberar conhecimento, modos de ser e estar, de vestir, assim como atitudes e posturas que são determinadas por interesses e relações de poder, produzem cultura. Nesse processo, buscam exercer o poder através de estratégias que contribuem para a fixação de identidades. Mas o processo de significação de seus discursos não ocorre de forma homogênea ou unilateral. Nesse aspecto, contribuem novamente Costa, Silveira e Sommer (2003) ao estabelecerem que

[...] É na esfera cultural que se dá a luta pela significação, na qual os grupos subordinados procuram fazer frente à imposição de significados que sustentam os interesses dos grupos mais poderosos. Nesse sentido, os textos culturais são o próprio local onde o significado é negociado e fixado (COSTA, SILVEIRA, SOMMER, 2003, p. 23).

De acordo com esse campo, toda instância cultural possui uma pedagogia e, por isso, cada uma produz um processo de educação apoiado em relações de poder. Entretanto, o poder aqui não é concebido como algo destrutivo, mas sim produtivo. Foucault (2015) aponta que o poder produz, nas palavras do autor

[...] o que faz com que o poder se mantenha e que seja aceito é simplesmente que ele não pesa só como força que diz não, mas que de fato ele permeia, produz coisas, induz ao prazer, forma saber, produz discurso (FOUCAULT, 2015, p. 45).

Do mesmo modo que a educação e a cultura estão envolvidas com o poder, elas produzem processos de transformação de subjetividades e identidades (SILVA, 2009). Nesse sentido, pelo fato de estarem intrinsecamente ligadas ao poder na formação de 
sujeitos, educação e cultura estão mutuamente implicadas em seus processos de produção.

Assim como o conceito de cultura passou por transformações ao longo da história, o conceito de pedagogia também foi se ampliando, a partir da percepção de que toda relação humana produz modificações nos sujeitos, portanto são educativas. $\mathrm{O}$ escritor francês Antoine de Saint-Exupéry, na célebre e mundialmente conhecida frase da obra $O$ Pequeno Príncipe escreve que "aqueles que passam por nós, não vão sós, não nos deixam sós. Deixam um pouco de si, levam um pouco de nós".

Os processos educativos, portanto, não se restringem ao espaço escolar, mas envolvem todas as instituições e artefatos culturais. Por isso a afirmação de que toda instância cultural é também pedagógica, pois resulta em um processo educativo. Sobre a relação entre pedagogia e cultura, é possível entender que

[...] se a pedagogia está implicada nas operações que fazem parte da produção
das pessoas, ela encontra-se, centralmente, também em contínua relação com
a cultura. Contudo, essa relação não deixa de implicar, do mesmo modo, em
aprendizagens que se dão sobre atuações sobre si mesmo, produzindo tanto
ideias quanto comportamentos (CAMOZZATO, 2014, p. 585).

Educação e pedagogia estão mutuamente implicadas com a cultura na formação de identidades associadas às necessidades vigentes, assim como na formação de modelos e padrões que produzem inclusões e exclusões. A pedagogia emerge justamente com o intuito de organizar a sociedade, de gerir as populações, de governar e disciplinar os corpos (CAMOZZATO, 2015). Ela serve à reprodução cultural por meio de técnicas e estratégias de governamento da população, pois a pedagogia, conforme Camozzato (2015, p. 516) "está implicada nos saberes e práticas disponibilizados para que as pessoas possam agir sobre si mesmas e sobre os outros".

Não basta apenas o cuidado e a vigilância sobre as próprias práticas, sobre o corpo, mas é necessário também fiscalizar o outro. Para que o governamento se torne possível, as diversas instituições sociais e artefatos culturais dispõem de estratégias e de discursos a fim de exercer o poder e controlar os sujeitos. Suas pedagogias são tão eficazes conforme as estratégias de sedução que utilizam.

A percepção de que não existe apenas uma única pedagogia, mas várias pedagogias em funcionamento na sociedade se propõe a evidenciar "[...] a operacionalidade de discursos específicos em artefatos que se dispõem a educar e 
produzir determinados tipos de sujeitos". (CAMOZZATO, 2014, p. 574). Tais pedagogias atuam em todos os espaços e contextos sociais de onde vem a origem de termos como: pedagogias da mídia, pedagogias do corpo, pedagogia do consumo, entre outras. Elas atuam sobre as pessoas "como pedagogias para ensinar saberes e práticas necessárias aos constantes ajustes às condições desse tempo-espaço preciso" (CAMOZZATO, 2015, p. 515).

Por meio dessas pedagogias, circulam visões específicas de mundo, gênero e sexualidade que nos interpelam diariamente. Costa, Silveira e Sommer (2003) apontam um conceito de pedagogia da mídia que contribui a esta reflexão, uma vez que se propõe a olhar as pedagogias culturais no artefato Modern Family. Nessa perspectiva,

[...] pedagogia da mídia refere-se à prática cultural que vem sendo problematizada para ressaltar essa dimensão formativa dos artefatos de comunicação e informação na vida contemporânea, com efeitos na política cultural que ultrapassam e/ou produzem as barreiras de classe, gênero sexual, modo de vida, etnia e tantas outras (COSTA, SILVEIRA, SOMMER, 2003, p. 57).

A partir do momento em que um artefato cultural coloca em visibilidade configurações familiares que fogem ao padrão culturalmente estabelecido, como o caso do seriado Modern Family, ela provoca a tradição, o pensamento fundamentalista ${ }^{3}$, põe em cheque determinados preconceitos e evidencia outras possibilidades de ser, de sexualidades, de gênero e de relações sociais, do mesmo modo que pode reproduzir discursos sociais consolidados.

Os seriados não são inocentes, assim como seu interesse não está relacionado apenas ao consumo ou ao entretenimento, mas sim possui interesses determinados que vão além dessas questões. Os textos e imagens que produzem têm objetivos específicos que refletem relações de poder.

Pode-se dizer, assim, que eles possuem pedagogias culturais, pois estão voltados a ensinar e formar sujeitos de certos tipos com determinados objetivos (CAMOZZATO, 2015). O conceito de pedagogias culturais é definido por Steinberg (1997 apud CAMOZZATO, 2014, p. 580) a partir da concepção de que

[...] a educação ocorre numa variedade de locais sociais, incluindo a escola, mas não se limitando a ela. Locais pedagógicos são aqueles onde o poder se

\footnotetext{
${ }^{3}$ Para Alfredo Veiga-Neto o fundamentalismo se caracteriza como "qualquer postura intelectual ou movimento social cujos partidários mantêm estrita, inarredável e intransigente obediência a determinados princípios fundamentais" (VEIGA-NETO, 2009, p. 78). 
organiza e se exercita, tais como as bibliotecas, TV, filmes, jornais, revistas, brinquedos, anúncios, videogames, livros, esportes, etc.

Esse conceito é uma ferramenta que contribui para problematizar outros espaços além da escola e que atuam na educação das pessoas, possibilitando um olhar para aquilo que ensinam, articulados à cultura e ao poder. Também contribui para evidenciar que esses espaços produzem ações nos sujeitos, de forma a subjetivá-los e conduzi-los de determinadas formas, isto é, produzem educação, mas que é distinta daquela que se produz na escola (ANDRADE, COSTA, 2015).

Assim, analisar as pedagogias culturais presentes no seriado Modern Family permite produzir um olhar para aquilo que ele ensina por meio de suas personagens, das relações que estabelecem, das imagens e textos que circulam, das relações de poder, das expressões de gênero e sexualidade, os quais giram em torno do parentesco e da família, produzindo o que se poderia chamar por Pedagogias Culturais de Família.

\section{O SERIADO MODERN FAMILY}

Modern Family é um seriado de comédia norte-americano que teve início no ano de 2009. Seus criadores são Christopher Lloyd e Steven Levitan e é produzido pela rede de televisão ABC (American Broadcasting Company). O seriado conta atualmente com 142 episódios, distribuídos em 8 temporadas. Os episódios não seguem uma sequência de fatos relacionados a uma mesma história, mas são pequenas narrativas que iniciam e concluem no mesmo episódio. Seu sucesso pode ser percebido com a conquista do Emmy ${ }^{4}$ de Melhor Série de Comédia em 2010, 2011, 2012, 2013 e 2014, além de outros Emmys e um Globo de Ouro.

As personagens principais que compõem o enredo são Jay Pritchett (Ed O’Neil) que é pai de Claire Dunphy (Julie Bowen) e Mitchel Pritchett (Jesse Tyles Ferguson). Em seu segundo casamento, Jay é casado com Gloria Delgado (Sofía Vergara). Ela é mãe de Manny (Rico Rodriguez), filho do primeiro casamento de Glória. Claire é casada com Phil Dunphy (Ty Burrell), pais de Luke (Nolan Gould), Alex (Ariel Winter) e Haley (Sarah Hyland). Mitchell é casado com Cameron Tucker (Eric Stonestreet), os quais adotaram uma bebê de origem vietnamita chamada Lily.

\footnotetext{
${ }^{4}$ Emmy é uma premiação dedicada a programas e profissionais da televisão, equivalente ao Oscar para o cinema. 
O seriado possibilita discussões que se relacionam a questões familiares atuais, como a adoção por casal homossexual, a homossexualidade, o divórcio, o relacionamento afetivo-sexual entre uma pessoa mais velha com outra mais nova, entre outras. Os episódios se propõem a evidenciar problemáticas vivenciadas no interior das famílias, discussões, preconceitos como homofobia, machismo e xenofobia, embora ao final de cada episódio seja retratado um "final feliz" para as disputas em questão, abordadas em cada episódio.

Pode-se refletir aqui com Escosteguy (2004), ao afirmar que os meios de comunicação de massa atuam na reprodução e na estabilidade cultural e social, contudo, “isso não se produz de forma mecânica, senão se adaptando continuamente às pressões e às contradições que emergem da sociedade, e englobando-as e integrando-as no próprio sistema cultural”. (ESCOSTEGUY, 2004, p. 147, grifos da autora).

Sendo assim, para que possa ser retratada uma família moderna ${ }^{5}$, segundo a concepção de seus produtores, é preciso que sua produção se adapte e englobe as questões que giram em torno dos debates contemporâneos sobre família. Desse modo, Modern Family retrata o que seus produtores entendem por família moderna, ou seja, aquela que não se configura mais apenas pela conjugalidade heterossexual e locus da reprodução filial, mas por outros arranjos que se unem por relações de afeto.

É nesse sentido que Mitchell e Cameron, o casal homossexual retratado no seriado, realizam o processo de adoção internacional, comum nos Estados Unidos, o que lhes possibilita adotar uma bebê vietnamita. Eles realizam o processo em segredo e apenas quando retornam do Vietnã com a filha é que fazem o comunicado à família. No princípio o pai de Mitchell reprova a ideia e afirma que os bebês precisam de uma mãe,

\footnotetext{
${ }^{5}$ Cabe aqui uma breve problematização sobre o termo moderno e seus correlatos modernismo e modernidade. Segundo Peters (2000), o modernismo pode ser entendido a partir de duas acepções, isto é, uma referência aos movimentos artísticos que ocorreram em meados do século XIX e outra, mais ligada ao termo moderno, correspondendo este à modernidade. Esta última acepção está associada a um determinado tempo histórico que se opõe à época medieval. As duas noções estão relacionadas entre si e correspondem à ideia de ruptura com o tradicional, enfatizando o presente. Nesse sentido, cabe alguns apontamentos sobre a expressão família moderna e sua escolha para nomear o seriado. O termo é comumente referido como aquela configuração nuclear, formada por pai, mãe e filhos/as (MELLO, 2005). Sendo assim, não corresponderia às configurações familiares que aparecem no seriado Modern Family, exceto por uma delas. Por outro lado, seus produtores podem associar o termo à noção de ruptura com o tradicional, no caso com a família tradicional, nuclear, evidenciando as configurações familiares do presente em que há o reconhecimento da sua vasta possibilidade de arranjos. É possível também pensarmos que este nome dado ao seriado constitui uma provocação para pensarmos que a família nuclear nunca foi absoluta, pois outros arranjos também são possíveis de ser encontrados no decorrer da história moderna.
} 
assim como a irmã que não os vê como capazes de criar um filho. Mas após Cameron apresentar-lhes Lily, toda a família se encanta com a mais nova integrante. Esta situação ocorre já no primeiro episódio da primeira temporada, situando o/a expectador/a da formação dessa família. Vale destacar também que nesta configuração é Mitchell o provedor, enquanto Cameron é quem cuida da casa.

O potencial dessa configuração familiar, formada por um casal homossexual que adota uma criança, em provocar novas formas de entender a família está nas palavras de Fonseca (2008, p. 769) “ao afastar a discussão da 'tradicional família nuclear', isto é, da procriação sexuada e da filiação biogenética, essas 'novas' formas familiares sacodem as bases de nossas crenças no que é "natural"'. E é por questionar o que seja natural que hoje, no Brasil, grupos fundamentalistas têm lutado em defesa da "natural" família nuclear, a exemplo do Projeto de Lei 6583/2013, intitulado Estatuto da Família.

A família de Jay, Gloria e Manny se constitui após a separação entre Jay e a mãe de Mitchell e Claire, bem como entre Gloria com o pai de Manny. Aqui aparece outra configuração familiar, a qual é denominada por família reconstituída.

Cabe destacar que Jay é um homem bem-sucedido e Gloria é uma mulher colombiana, de origem humilde, elegante, sedutora e muito mais nova que ele. Gloria é mãe de Manny, um garoto pré-adolescente, diferente das demais crianças pela sua postura intelectual e romântica, que escreve poesias e músicas para as garotas que quer conquistar, também mais velhas que ele. Manny é um garoto gordo e, ao fugir dos padrões de beleza culturalmente instituídos, é apontado que ele não terá chances com as garotas.

Claire tem dificuldades em aceitar a nova esposa do pai, por entender que ela casou-se apenas por interesse e oportunismo, levando em consideração as questões econômicas e geracionais que são bem diferentes entre Jay e Gloria. Gloria também deixa transparecer constantemente a contradição entre amar Jay e sentir falta do relacionamento com o pai de Manny.

Phil e Claire são pais de Haley, uma garota que adora usar roupas curtas, demonstrando ser o estereótipo da "patricinha"; Alex, a filha do meio que faz o papel de intelectual, caracterização dada inclusive por usar óculos; e Luke, filho mais novo, inocente, atrapalhado e que vive metendo-se em confusão. Phil exerce o papel de 
marido, provedor da família, fiel, mas cobiça outras mulheres, principalmente Gloria, a esposa de seu sogro. Em muitas cenas com o/as filho/as, demonstra mais infantilidade que os próprios. Claire é a mãe protetora e aquela que educa os filhos/as em oposição ao marido que parece não participar muito dessa função. Ela é uma dona de casa que parece exaurida com as funções de mãe, cuidadora, educadora, faxineira e cozinheira da casa.

Assim, o seriado recebeu algumas críticas do movimento feminista pelo machismo retratado nos papéis exercidos por Gloria e Claire como esposas restritas ao espaço doméstico, reproduzindo expectativas tradicionais de gênero sobre os locais adequados a homens e mulheres, isto é, o espaço social como sendo masculino e o espaço doméstico, feminino. Além disso, também foi questionada a ausência de demonstração de afeto entre Cameron e Mitchell, mas que já na segunda temporada essa questão foi atendida por uma cena em que os dois se beijam. (WIKIPEDIA, 2016).

Pode-se então questionar o que ensina este seriado? Quais as pedagogias culturais nele presentes? Para ajudar a responder a essas questões, Camozzato (2014, p. 587) esclarece que "no cotidiano das experiências comuns, na formulação dos modos de compreender o mundo, a si e aos outros, culturas e pedagogias estão articuladas e em funcionamento".

Nesse sentido, a partir do momento em que o seriado é assistido, ele passa a agir sobre as formas de compreender o mundo e de atribuir sentido a ele pelos/as seus/suas expectadores. Cada sujeito constrói significados para o seriado conforme os pressupostos e conhecimentos anteriores, de forma que uma pessoa embasada em princípios fundamentalistas pode vir a entender o seriado como algo impróprio, ou se sentir provocada a repensar seus valores morais. Já uma pessoa que apoia outros arranjos familiares tenderá a aprovar o seriado.

Modern family fala a partir da cultura norte-americana, suas personagens são brancas e pessoas de classe média, ensinando determinados comportamentos, como padrões de consumo e beleza. As mulheres são magras e elegantes e apenas Cameron e Manny são gordos, motivo pelo qual Cameron é criticado pelo namorado - conforme eles mesmo se intitulam até que constituem casamento, no final da $5^{\mathrm{a}}$ temporada. 
As três famílias possuem uma estrutura patriarcal, pois mesmo na família de Mitchell e Cameron, Mitchell é quem trabalha fora e exerce um papel menos sentimental, já Cameron fica em casa e é sentimental, comovendo-se com as situações do cotidiano o que o faz querer ajudar a todos/as. Desse modo, mesmo que sejam um casal homossexual, um exerce uma função concebida mais masculina, enquanto o outro é colocado numa posição produzida socialmente como sendo feminina.

Sobretudo, para que sejam reconhecidas como famílias, é preciso que possuam filhos/as, reproduzindo o pressuposto que são eles/as que dão sentido à família. Essa questão é retratada no primeiro episódio quando Mitchell antes de anunciar que adotou uma criança afirma que tanto ele quanto Cameron sentiam que algo lhes faltava.

O seriado, por meio de suas pedagogias culturais, atua no governamento dos corpos ao mostrar as relações que são estabelecidas no interior da família. Uma das estratégias utilizadas é ressaltar a ausência de algo, como do cuidado com o corpo, no caso de Cameron e Manny, a ausência de amadurecimento no caso de Phil, a ausência de inteligência de Luke. Camozzato (2014, p. 586) afirma que

[...] criar e/ou apontar uma "falta" é uma estratégia de governo: é reconhecendo a incompletude que se pode voltar a atuar sobre si para preenche-la a partir de alguma das muitas lições, recomendações, prescrições, etc., disponíveis no contexto social em que se está.

Mesmo quando retratam o excesso, como do cuidado materno de Claire e Gloria, podem querer significar a ausência de algo, como o cuidado consigo mesma, de paciência e tranquilidade no caso de Claire e da necessidade de colocar limites no filho por parte de Gloria.

Embora a série possibilite pensar outras configurações familiares, ela reproduz padrões de gênero acordados à ordem heterossexual, de modo que exercem poder sobre a constituição das subjetividades. São pedagogias culturais que ensinam formas de ser família dentro de determinada cultura, evidenciando práticas sociais para homens e mulheres, meninos e meninas, assim como padrões de corpo, de classe, gênero e sexualidade. Ainda que apresente uma família homossexual, esta obedece a padrões heterossexuais, reproduzindo a heteronormatividade. 


\section{CONSIDERAÇÕES FINAIS}

Nos episódios do seriado estão presentes discursos que fazem circular signos e significados para modos de ser família, bem como pai, mãe, avô, filho, filha, tio e tia. São pedagogias culturais de família que exercem sobre seus/suas expectadores/as um processo de educação que ensina determinadas posições de sujeitos conforme o gênero, a sexualidade e a classe social que ocupam. Essas posições interpelam os sujeitos de forma a contribuir na forma de perceber o mundo e construir sua identidade.

Modern Family, como artefato cultural, faz circular expectativas e modos de ser e viver que lhe são contemporâneos, refletindo sua adaptação às transformações culturais. Entretanto, as cenas que exibe são reflexos de escolhas a partir de interesses particulares e relações de poder que negociam o que pode ser exibido e o que não é legítimo de o ser.

Apesar dessas escolhas, o/a expectador/a não se apropria dessas posições de sujeito sem que passem por processos de subjetivação e significação que são negociados, isto é, nesses processos há resistências e lutas identitárias pelo fato de que o poder se exerce em relação, pois, lembrando Foucault (2015, p. 45) é preciso considerar o poder "[...] como uma rede produtiva que atravessa todo o corpo social mais do que uma instância negativa que tem por função reprimir".

Ao contribuir na formação de identidades, não se deve ter em mente o seriado como um artefato de repressão dos sujeitos, exercendo um processo de manipulação sem resistências, mas entendê-lo na sua potencialidade de produção da diferença. Nessa direção concordam Costa, Silveira e Sommer (2003, p. 58) ao afirmarem que “[...] o que precisamos continuar a investigar, discutir, destacar, mostrar é a positividade do poder, sua capacidade de produzir subjetividades e identidades".

As pedagogias culturais de família presentes em Modern Family são, por isso, produtoras de novas identidades de ser pai, mãe, filho ou filha, bem como de todo um conjunto de relações de parentesco e conjugalidade que mobilizam os sujeitos na constituição de suas subjetividades.

\section{REFERÊNCIAS}

ANDRADE, P. D.; COSTA, M. V. Usos e possibilidades do conceito de pedagogias culturais nas pesquisas em estudos culturais em educação. Textura, Canoas, v. 17, n. 
34, p. 48-63, mai./ago. 2015. Disponível em: $<$ http://www.periodicos.ulbra.br/index.php/txra/article/viewFile/1501/1140> Acesso em: 15 mai. 2016.

CAMOZZATO, V. C. Entre a pedagogia legisladora e as pedagogias intérpretes. Revista Brasileira de Educação, Campinas, São Paulo, v. 21, n. 61, 2015. Disponível em: $\quad<$ http://www.scielo.br/pdf/rbedu/v20n61/1413-2478-rbedu-20-61-0501.pdf $>$ Acesso em: 15 mai. 2016.

CAMOZZATO, V. C. Pedagogias do Presente. Educação \& Realidade, Porto Alegre, v. 39, n. 2, abr./jun. 2014. p. 573-593. Disponível em: $<$ http://www.scielo.br/pdf/edreal/v39n2/v39n2a12.pdf>Acesso em: 15 mai. 2016.

COSTA, M. V.; SILVEIRA, R. H.; SOMMER, L. H. Estudos culturais, educação e pedagogia. Revista Brasileira de Educação, Campinas, São Paulo, n. 23, p. 36-61, 2003. Disponível em: <http://www.scielo.br/pdf/rbedu/n23/n23a03.pdf > Acesso em: 15 mai. 2016.

DIAS, M. B. Manual de Direito das Famílias. São Paulo: Revista dos Tribunais, 2015.

ESCOSTEGUY, A. C. Estudos Culturais: uma introdução. In: SILVA, Tomas Tadeu da. (org.) O que é, afinal, Estudos Culturais? Belo Horizonte: Autêntica, 2004. p. 133-166.

FARIAS, M. de O; MAIA, A. C. B. Adoção por homossexuais: a família homoparental sob o olhar da psicologia jurídica. Curitiba: Juruá, 2009.

FISCHER, R. M. B. O dispositivo pedagógico da mídia: modos de educar na (e pela) TV. Educação e Pesquisa, São Paulo, v. 28, n. 1, p. 151-162, Jun. 2002. Disponível em: $\quad<$ http://www.scielo.br/scielo.php?script=sci_arttext\&pid=S151797022002000100011\&lng=en\&nrm=iso>. Acesso em: 23 Mar. 2016.

FONSECA, C. Homoparentalidade: novas luzes sobre o parentesco. Estudos Feministas, v. 16, n. 3, p. 769-783, 2008.

FOUCAULT, M. Microfísica do Poder. 3.ed. Rio de Janeiro: Paz e Terra, 2015.

GATO, J. Famílias formadas por lésbicas e gays: as mães, os pais, os filhos e os outros. FERNANDES, O. M.; MAIA, C. (org.) A família portuguesa do século XIX. Lisboa: Parsival, 2015. p. 79-86.

GIROUX, H. A. Memória e pedagogia no maravilhoso mundo da Disney. In. SILVA, T. T. da. (org.) Alienígenas na sala de aula: uma introdução aos estudos culturais em educação. Petrópolis: Editora Vozes, 2005. p. 132-158.

LIMA, P. C. L. de. De olho na tela: O consumo de séries de TV norte-americanas através da internet. Trabalho de Conclusão de Curso, Faculdade de Comunicação Social. Universidade Federal de Juiz de Fora, 2013. Disponível em: $<$ http://www.ufjf.br/facom/files/2013/05/Monografia-De-Olho-na-tela-O-consumo-des\%C3\%A9ries-de-TV-norte.pdf > Acesso em: 20 mar. 2016.

MELLO, L. Novas famílias: conjugalidade homossexual no Brasil contemporâneo. Rio de Janeiro: Garamont, 2005.

MODERN FAMILY. In. ABC Television Network. Disponível em: $<$ http://abc.go.com/shows/modern-family/about-the-show $>$ Acesso em 16 mar. 2016 
MODERN FAMILY. In. WIKIPÉDIA, a enciclopédia livre. Flórida: Wikimedia Foundation, 2016. Disponível em: <https://pt.wikipedia.org/wiki/Modern_Family> Acesso em: 10 mai. 2016.

PETERS, M. Estruturalismo, pós-estruturalismo e pós-modernismo. In.: Pósestruturalismo e Filosofia da Diferença. Belo Horizonte: Editora Autêntica, 2000. p. 09-46.

SILVA, T. T. da. A pedagogia como cultura, a cultura como pedagogia. In: SILVA, T. T. da. Documentos de Identidade: uma introdução às teorias do currículo. Belo Horizonte: Autêntica, 2009. p. 139-144.

VEIGA-NETO. A. Uma vila voltada para trás. In: GALLO, S. \& VEIGA-NETO, A. (org.) Fundamentalismo \& Educação. Belo Horizonte: Autêntica Editora, 2009. p. 67 106. 